\title{
Descriptive Analysis of Participants Before and After Attending the Workshop "Meditation as a Form of Relaxation" METHADONE 2021
}

\author{
Marselia Febriyanti Sihotang ${ }^{1}$, Chelssi Gloria Tessari ${ }^{1}$, Jason ${ }^{1}$, Sri Wijayanti \\ Sulistyawati ${ }^{1 *}$
}

\author{
${ }^{1}$ Medical Undergraduate Program, Faculty of Medicine Universitas Airlangga, J1. Mayjen Prof. Dr. \\ Moestopo No.47, 60132, Surabaya, East Java, Indonesia \\ ${ }^{2}$ Departement of Parasitology, Faculty of Medicine Universitas Airlangga, J1. Mayjen Prof. Dr. \\ Moestopo No.47, 60132, Surabaya, East Java, Indonesia \\ *email: sri-w-s@fk.unair.ac.id
}

\begin{abstract}
COVID-19 pandemic has caused a shift in work and school systematics into a predominantly online system. Aside from benefits of enabling work and teaching done without face-to-face interaction, online meeting platforms such as Zoom and Google meet also has some unwanted negative effects, among them is the phenomena called zoom fatigue. One of the ways to overcome zoom fatigue is through relaxation, which can be done by performing meditation. As a mean of providing resources which can help participants to further their knowledge on the topic of meditation, we conduct the workshop titled "Meditation as a Form of Relaxation". This article describe the general demography of participants of this workshop, as well as their knowledge, interest, and capability of doing meditation prior to and after the workshop have been held.
\end{abstract}

Keywords: COVID-19; meditation; relaxation; workshop; zoom fatigue

\section{Introduction}

Coronavirus Disease 2019 (COVID-19) is a respiratory infection caused by a novel type of coronavirus, SARS-CoV-2. As of the $24^{\text {th }}$ of July, 2021, COVID-19 cases in Indonesia have reached 3.03 million confirmed cases after experiencing a $44 \%$ spike in infections from 12-18 July[1]. The World Health Organization has declared this disease as a global pandemic since March of 2020 and has caused many changes in society's way of life, behavior, and social order. The straightforward transmission process of the coronavirus between individuals is one of the factors causing the rapid pace of COVID-19 growth into a global pandemic. The method of transmission of this virus is through droplets that can be transmitted through close contact, therefore demanding the enforcement of social distancing so that the spread of the virus can be contained[2]. Indonesian government have established some strategies to control COVID-19 cases in Indonesia, among them are by implementing clean and healthy living behavior, as well as Work From Home (WFH) for workers who can do work online and School From Home (SFH) for students and college students to minimize the spread of the virus[3].

The application of WFH and SFH has caused a systematic shift from face-to-face interaction to mainly being done online. Online meeting platforms such as Zoom, Google Meet, and other applications has made it 
possible for workers to work from their respective homes. However, with the increase in online meetings, this is followed by the emergence of the phenomenon termed 'zoom fatigue'. The unclear difference of work and being at home, which has distinct lifestyle factors and social aspects, can impact negatively on a person's mental and physical health[4][5]. Online meetings require a higher focus than face-to-face meetings due to the lack of ability to rely on nonverbal communication as a way of interpretation[6]. Requirement of more focus combined with the less than ideal home atmosphere as a work setting, where there are many diversions, will cause online meetings to be more physically and mentally demanding for workers. This is bound to cause further problems and diseases, especially when done for long hours at a time[7]. Applying meditation and mindfulness in everyday life is one of the ways to overcome this fatigue[8]. Meditation practices strongly enhances our mind to be calmer and more aware, it has been applied for over a millennium by different type of groups, hence this would be a very beneficial method to provide mental and physical support[9]. Several other pieces of research of intervention using meditation also show that, after being given the meditation intervention, the level of people's anxiety decreases during the COVID-19 pandemic. It also shows that nonpractitioner has a higher level of distress than meditation practitioner with a quite significant difference[10][11]. Principles of mindfulness give a chance to workers to find a way in the extremely stressful situations during this COVID-19 pandemic[12]. Therefore, the authors took the initiative to hold an open workshop titled "Meditation as Form of Relaxation" and invited a certified meditation teacher as an instructor. By holding this workshop, we hope the participants will acquire the skill sets needed to do meditation in order to relax and overcome the fatigue they experience, especially zoom fatigue.

\section{Materials and Methods}

This research is a descriptive research with survey as the method of collecting data. Data collection was carried out by collecting participant demographic data and data regarding participants' knowledge, abilities, and interests in meditation before (pre-test) and after (post-test) the workshop was held. There are a total of 1240 participants who filled out both the pre-test and the post test and thus are qualified to be the sample of this research. The data is then presented in frequency tables and are analyzed descriptively.

\section{Results and Discussion}

\section{General Characteristic of the Samples}

Based on secondary data from the 2012 National Health Interview Survey (NHIS), meditation is one of the most recognized applications of complementary and alternative medicine (CAM) by people in the United States. The sample in this study was 34,525 people who had completed the 2012 NHIS interview and were also interviewed about the use of alternative medicine. From the data collected, the prevalence of meditation during the last 12 months in the 18-24 age group was $10.15 \%$, while the 25-44 age group was 37.08\%[13]. Among all age groups, the prevalence of doing meditation is higher in women $(61.45 \%)$ when compared to men (36.55\%)[14]. We found different things in the age category of the participants of the METHADONE workshop with the topic "Meditation as a Form of Relaxation" wherein the workshop we conducted, participants were dominated by the age category of late teens (17-25 years old) as many as 957 people (77.2 $\%)$. As for gender, secondary data from NHIS corresponds to participants in the METHADONE workshop, which is dominated by women, as many as 1141 participants $(92 \%)$. The age and gender categories of METHADONE workshop participants can be seen in Table 1 and 2, respectively.

Table 1. Frequency distribution of workshop participants' age 


\begin{tabular}{lcccc}
\hline & Frequency & Percent & Valid Percent & Cumulative Percent \\
\hline $\mathbf{1 1 7}$ & 271 & $21.85 \%$ & 21.85 & 21.9 \\
\hline $\mathbf{1 7 - 2 5}$ & 957 & $77.18 \%$ & 77.18 & 99.0 \\
\hline $\mathbf{2 6 - 3 5}$ & 12 & $0.97 \%$ & 0.97 & 100 \\
\hline$>\mathbf{3 5}$ & 0 & 0 & 0 & 100 \\
\hline Total & 1240 & 100.0 & 100.0 & \\
\hline
\end{tabular}

Table 2. Distribution of gender of workshop participants

\begin{tabular}{ccccc}
\hline & \multicolumn{3}{c}{ Gender } & Cumulative Percent \\
\hline Male & Frequency & Percent & Valid Percent & 8.0 \\
\hline Female & 99 & 8.0 & 8.0 & 100.0 \\
\hline Total & 1141 & 92.0 & 92.0 & \\
\hline
\end{tabular}

\section{Differences in Pre-Test and Post-Test Scores}

Table 3. Pre-Test Scores for Workshop Participants

\begin{tabular}{ccccc}
\hline \multicolumn{5}{c}{ Pre-test } \\
\hline $\mathbf{0}$ & Frequency & Percent & Valid Percent & Cumulative Percent \\
\hline $\mathbf{1}$ & 413 & 33.3 & 33.3 & 33.3 \\
\hline $\mathbf{2}$ & 496 & 40.0 & 40.0 & 73.3 \\
\hline $\mathbf{3}$ & 242 & 19.5 & 19.5 & 92.8 \\
\hline $\mathbf{4}$ & 74 & 6.0 & 6.0 & 98.8 \\
\hline $\mathbf{5}$ & 9 & .7 & .7 & 99.5 \\
\hline Total & 6 & .5 & .5 & 100.0 \\
\hline
\end{tabular}

Table 3 shows the participants' scores when given 5 multiple choice questions regarding meditation before joining METHADONE. The aim of this pre-test is to inquire participants' pre-existing knowledge of meditation prior to the material given in the workshop. From the table, it is known that the number of participants who scored 0 during the pre-test was 413 participants $(33.3 \%)$ and the number of participants with a score of 5 was 6 participants $(0.5 \%)$. Approximately $93 \%$ of the participants only answered between 0 2 questions correctly. The complete survey questions can be seen in appendix A.

Table 4. Post-Test Results of Workshop Participants

\begin{tabular}{ccccc}
\hline & \multicolumn{3}{c}{ Post-test } \\
\hline $\mathbf{0}$ & Frequency & Percent & Valid Percent & Cumulative Percent \\
\hline $\mathbf{1}$ & 176 & 14.2 & 14.2 & 14.2 \\
\hline $\mathbf{2}$ & 299 & 24.1 & 24.1 & 38.3 \\
\hline $\mathbf{3}$ & 281 & 22.7 & 22.7 & 61.0 \\
\hline $\mathbf{4}$ & 215 & 17.3 & 17.3 & 78.3 \\
\hline $\mathbf{5}$ & 171 & 13.8 & 13.8 & 92.1 \\
\hline Total & 98 & 7.9 & 7.9 & 100.0 \\
\hline
\end{tabular}


Table 4 shows the participants' scores after participating in the METHADONE workshop. From the table, it's known that the number of participants who scored 0 decreased 19.1\%, from 237 participants to 176 participants (14.2\%). Participants with a score of 5 increased $7.4 \%$ to 98 participants (7.9\%). Moreover, the amount of people scoring 4-5 points increased from 15 in the pre-test to 269 in the post-test. These data indicate an increase in participants' knowledge about meditation as a form of relaxation after attending the METHADONE workshop.

Table 5. Experiences of Participants Meditating Before Workshop

\begin{tabular}{ccccc}
\hline & Frequency & Percent & Valid Percent & Cumulative Percent \\
\hline $\mathbf{1}$ & 160 & 12.9 & 12.9 & 12.9 \\
\hline $\mathbf{2}$ & 257 & 20.7 & 20.7 & 33.6 \\
\hline $\mathbf{3}$ & 408 & 32.9 & 32.9 & 66.5 \\
\hline $\mathbf{4}$ & 238 & 19.2 & 19.2 & 85.7 \\
\hline $\mathbf{5}$ & 177 & 14.3 & 14.3 & 100.0 \\
\hline
\end{tabular}

Table 5 shows whether participants ever meditated before and the frequency of meditation. The meditation frequencies of the participants are described in the range of 1 (never) to 5 (very often). The number of participants who answered 1 (never) was 160 participants (12.9\%), and those who answered 5 (very often) were 177 participants $(14.3 \%)$.

Table 6. Experiences of Participants Meditating After Workshop

\begin{tabular}{ccccc}
\hline & Frequency & Percent & Valid Percent & Cumulative Percent \\
\hline $\mathbf{1}$ & 105 & 8.5 & 8.5 & 8.5 \\
\hline $\mathbf{2}$ & 206 & 16.6 & 16.6 & 25.1 \\
\hline $\mathbf{3}$ & 323 & 26.0 & 26.0 & 51.1 \\
\hline $\mathbf{4}$ & 275 & 22.2 & 22.2 & 73.3 \\
\hline $\mathbf{5}$ & 331 & 26.7 & 26.7 & 100.0 \\
\hline Total & 1240 & 100.0 & 100.0 & \\
\hline
\end{tabular}

Table 6 shows the interest of participants to meditate in the future and the frequency after joining METHADONE. The mediation frequencies of the participants are described in a range of 1 (never) to 5 (very often). The number of participants who answered 1 (never) was 105 participants (8.5\%), and those who answered 5 (very often) were 331 (26.7\%). This had increased $12.4 \%$ compared to before the workshop. This indicates that more people are interested in doing more meditation after exposure to materials delivered in this workshop.

Table 7. Reasons for Participants to Meditate

\begin{tabular}{cc}
\hline Reason & Frequency \\
\hline Keep oneself grounded & 142 \\
\hline Relieve stress & 1053 \\
\hline Increase self-comfort & 538 \\
\hline Transcend ego & 127 \\
\hline Other reasons & 12 \\
\hline Never & 38 \\
\hline
\end{tabular}

Table 7 shows the various reasons participants meditate. One participant can choose more than one reason. Among the available answer choices, most participants, as many as 1053 participants, chose the reason to release stress, then the second most chosen reason was to increase comfort, followed by to ground her/himself and to transcend the ego. Other reasons answered by participants such as for religious activities, overcoming 
sleeplessness, for school activities, relieving anxiety, to achieve peace of mind, overcoming eye strain, and practicing concentration. As many as 38 other participants did not choose any answer because they had never done meditation.

\section{Participants' Desire to Learn Meditation Correctly Before and After the Workshop}

Table 8. Participants' Desire to Learn Meditation Correctly Before the Workshop

\begin{tabular}{ccccc}
\hline & Frequency & Percent & Valid Percent & Cumulative Percent \\
\hline $\mathbf{1}$ & 34 & 2.7 & 2.7 & 2.7 \\
\hline $\mathbf{2}$ & 115 & 9.3 & 9.3 & 12.0 \\
\hline $\mathbf{3}$ & 291 & 23.6 & 23.5 & 35.5 \\
\hline $\mathbf{4}$ & 333 & 26.9 & 26.9 & 62.3 \\
\hline Total & 467 & 37.7 & 37.7 & 100.0 \\
\hline
\end{tabular}

Table 8 shows the participants' desire to learn meditation properly before the METHADONE workshop. Participants' desire to learn meditation is described as a numbered range of 1 (very unwilling) to 5 (very eager). From the table, 34 participants $(2.7 \%)$ answered number 1, which means they really do not want to learn meditation properly, and 467 participants $(37.7 \%)$ chose number 5, which means they really want to learn meditation properly.

Table 9. Participants' Desire to Learn Meditation Correctly After the Workshop

\begin{tabular}{ccccc}
\hline & Frequency & Percent & Valid Percent & Cumulative Percent \\
\hline $\mathbf{1}$ & 8 & .6 & .6 & .6 \\
\hline $\mathbf{2}$ & 26 & 2.1 & 2.1 & 2.7 \\
\hline $\mathbf{3}$ & 130 & 10.5 & 10.5 & 13.2 \\
\hline $\mathbf{4}$ & 352 & 28.4 & 28.4 & 41.6 \\
\hline $\mathbf{5}$ & 724 & 58.4 & 58.4 & 100.0 \\
\hline Total & 1240 & 100.0 & 100.0 & \\
\hline
\end{tabular}

Table 9 shows the participants' desire to learn meditation properly after the METHADONE workshop.The participants' desire to learn meditation described the same as before, number 1 (very unwilling) to number 5 (very eager). From the table, there was a decrease in participants who answered 1 (8 participants [0.6\%]), and the number of participants who answered number 5 , which means they are very eager to learn meditation, also increased by 724 participants $(58.4 \%)$. The number of participants who did not want to learn meditation decreased by $2.1 \%$, and the number of participants who really wanted to learn to meditate increased by $20.7 \%$. This means that there is a significant increase in the participants' desire and interest to learn meditation properly after attending the METHADONE workshop.

\section{Participants' Understanding of the Right Way to Meditate Before and After the Workshop}

Table 10. Participants' Understanding of How to Meditate Correctly Before the Workshop

\begin{tabular}{ccccc}
\hline & Frequency & Percent & Valid Percent & Cumulative Percent \\
\hline $\mathbf{1}$ & 264 & 21.3 & 21.3 & 21.3 \\
\hline $\mathbf{2}$ & 419 & 33.8 & 33.8 & 55.1 \\
\hline $\mathbf{3}$ & 357 & 28.8 & 28.8 & 83.9 \\
\hline $\mathbf{4}$ & 93 & 7.5 & 7.5 & 91.4 \\
\hline $\mathbf{5}$ & 107 & 8.6 & 8.6 & 100.0 \\
\hline Total & 1240 & 100.0 & 100.0 & \\
\hline
\end{tabular}

Table 10 shows the participants' understanding of meditation before the METHADONE workshop. From 
the table, it was found that 264 participants $(21.3 \%)$ answered number 1 , which means they do not really understand how to meditate, and as many as 107 participants $(8.6 \%)$ chose number 5 , which means that they have a better understanding about how to meditate correctly.

Table 11. Participants' Understanding of How to Meditate Correctly After the Workshop

\begin{tabular}{ccccc}
\hline & Frequency & Percent & Valid Percent & Cumulative Percent \\
\hline $\mathbf{1}$ & 15 & 1.2 & 1.2 & 1.2 \\
\hline $\mathbf{2}$ & 40 & 3.2 & 3.2 & 4.4 \\
\hline $\mathbf{3}$ & 162 & 13.1 & 13.1 & 17.5 \\
\hline $\mathbf{4}$ & 446 & 36.0 & 36.0 & 53.5 \\
\hline $\mathbf{5}$ & 577 & 46.5 & 46.5 & 100.0 \\
\hline Total & 1240 & 100.0 & 100.0 & \\
\hline
\end{tabular}

Table 11 shows the participants' knowledge of meditation after the METHADONE workshop. Participants' understanding of how to meditate correctly is measured by a number of 1 (does not understand very well) to 5 (understands very well). From the table, it was found that 15 participants (1.2\%) answered number 1 , which means they did not understand very well the correct manners to meditate. There is a decrease of $20.1 \%$ compared to the number of participants who did not understand before attending the workshop. Whereas 577 participants $(46.5 \%)$ chose number 5 , which means they have a good grasp on ways to meditate correctly. There is a $37.9 \%$ increase compared to before the workshop, implying that METHADONE workshop participants experienced an increase in understanding of how to meditate correctly.

\section{The Ability of Participants to Meditate Correctly Before and After Workshop}

Table 12. Ability of Participants to Meditate Correctly Before Workshop

\begin{tabular}{ccccc}
\hline & Frequency & Percent & Valid Percent & Cumulative Percent \\
\hline $\mathbf{1}$ & 271 & 21.9 & 21.9 & 21.9 \\
\hline $\mathbf{2}$ & 439 & 35.4 & 35.4 & 57.3 \\
\hline $\mathbf{3}$ & 331 & 26.7 & 26.7 & 84.0 \\
\hline $\mathbf{4}$ & 106 & 8.5 & 8.5 & 92.5 \\
\hline $\mathbf{5}$ & 93 & 7.5 & 7.5 & 100.0 \\
\hline Total & 1240 & 100.0 & 100.0 & \\
\hline
\end{tabular}

Table 12 shows the participants' ability to meditate correctly before the METHADONE workshop. The participants' ability to meditate correctly was measured with a number ranging from 1 (very poor) to 5 (competent). From the table, it was found that 271 participants $(21.9 \%)$ answered number 1, which means they have very poor skill to meditate correctly, and 93 participants $(7.5 \%)$ chose number 5 , which is competent of meditating correctly. The majority of respondents $(35.4 \%)$ chose number 2 , signifying a poor ability to correctly perform meditation.

Table 13. Ability of Participants to Meditate Correctly After Workshop

\begin{tabular}{ccccc}
\hline & Frequency & Percent & Valid Percent & Cumulative Percent \\
\hline $\mathbf{1}$ & 18 & 1.3 & 1.3 & 1.3 \\
\hline $\mathbf{2}$ & 40 & 3.2 & 3.2 & 4.5 \\
\hline $\mathbf{3}$ & 227 & 18.3 & 18.3 & 22.8 \\
\hline $\mathbf{4}$ & 462 & 37.3 & 37.3 & 60.1 \\
\hline $\mathbf{5}$ & 495 & 39.9 & 39.9 & 100.0 \\
\hline Total & 1240 & 100.0 & 100.0 & \\
\hline
\end{tabular}

Table 13 shows the participants' ability to meditate properly after the METHADONE workshop. The participants' ability to meditate correctly was measured with a range of 1 (very poor) to 5 (competent). From 
the table, it was found that as many as 16 participants $(1.3 \%)$ answered number 1 , which means they are not very capable of meditating properly; this decreased $20.6 \%$ compared to before. On the other hand, 495 participants $(39.9 \%$ ) chose number 5, which is very capable of meditating correctly. The amount of people with the same answer also experienced a very significant increase (32.4\%) compared to before the workshop, suggesting that METHADONE workshop participants experienced an overall increase in their ability to meditate correctly after attending the METHADONE workshop.

\section{Conclusion}

Based on the research results, the workshop is dominated by females (1141 people [92\%]). The dominating age is from the late adolescence group (age 17-25 years) consisting of 957 people (77.2\%). The pre-test and post-test scores of workshop participants have increased overall, indicating an increase in workshop participants' understanding and ability to meditate with the correct method as shown in the fourth and fifth survey questions (increased $37.9 \%$ and $32.4 \%$, respectively). The most common reasons for participants to meditate are to reduce stress, followed by to increase self-comfort, to ground themselves, to transcend the ego, and other reasons such as for religious activities, to overcome insomnia, for school activities, to remove anxiety, to overcome strain on the eyes, and to practice concentration. In addition, the interest and desire of workshop participants to meditate also increased quite significantly $(20.7 \%)$.

\section{Acknowledgements}

The authors wished to thank dr. Sri Wijayanti, M.Imun as a mentor who has accompanied us to prepare the METHADONE events to be held properly. Special thanks to our workshop instructor, Tsamara Fahrana, who has given her time and knowledge so that this workshop can be beneficial for all participants.

\section{REFERENCES}

1. World Health Organization, 2021. COVID-19 Weekly Epidemiological Update - 20 July 2021.:WHO Team: Emergency Response.

2. Kemenkes, R. I., 2020. Pedoman Kesiapsiagaan Menghadapi Infeksi Coronavirus (2019-nCoV). Jakarta: Ditjen Pencegahan dan Pengendalian Penyakit Kemenkes RI.

3. Karo, M. B., 2020. Perilaku hidup bersih dan sehat (PHBS) strategi pencegahan penyebaran Virus Covid-19. s.1.:Prosiding Seminar Nasional Hardiknas.

4. Allen, T. D., Golden, T. D. \& Shockley, K. M., 2015. How Effective Is Telecommuting? Assessing the Status of Our Scientific Findings.. s.l.: Psychological Science in the Public Interest

5. Xiao, Y., Becerik-Gerber, B., Lucas, G. \& Roll, S. C., 2021. Impacts of Working From Home During COVID-19 Pandemic on Physical and Mental Well-Being of Office Workstation Users.: Journal of Occupational and Environmental Medicine

6. Jiang, M., 2020. The reason Zoom calls drain your energy.:BBC.com.

7. Eddleston, K. A. \& Mulki, J., 2017. Toward Understanding Remote Workers' Management of Work- 
Family Boundaries: The Complexity of Workplace Embeddedness.:SAGE Journals.

8. Maheu, M. \& Wright, S., 2020. Trouble-Shooting “Zoom Fatigue” in the Era of Telehealth.:American Psychological Association.

9. Behan, C., 2020. The benefits of meditation and mindfulness practices during times of crisis such as COVID-19.: Irish Journal of Psychological Medicine

10. Hasina, S. N., Noventi, I., Livana, P. \& Hartono, D., 2021. Mindfulness Meditation Based on Spiritual Care to Reduce Community Anxiety due to the Impact of Pandemic Coronavirus Disease.: Open Access Macedonian Journal of Medical Sciences

11. Zhu, J. L. et al., 2021. Mindfulness practice for protecting mental health during the COVID-19 pandemic.:Translational Psychiatry.

12. Cowling, W. R., 2021. Feature Sections: Mindfulness/Meditation and COVID-19. s.1.:Journal of Holistic Nursing

13. United States Department of Health and Human Services. Centers for Disease Control and Prevention. National Center for Health Statistics, 2012, National Health Interview Survey

14. Burke, A., Lam, C. N., Stussman, B. \& Yang, H., 2017. Prevalence and patterns of use of mantra, mindfulness and spiritual meditation among adults in the United States.: BMC Complementary and Alternative Medicine 


\section{Appendix A. Survey Questions}

\section{General Characteristic}

1. E-mail

2. Name

3. Age

4. Gender

Female

5. City of Origin :

6. I have meditated before

mark only one square

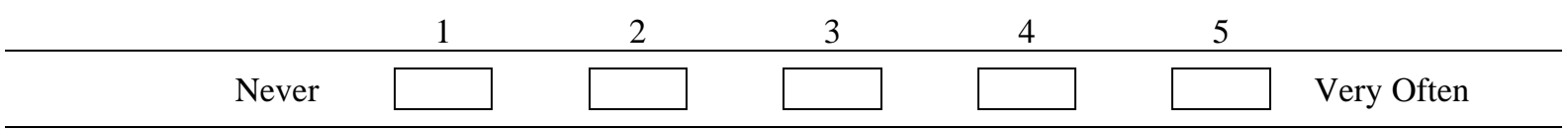

7. Why do you meditate?

mark all appropriate squares

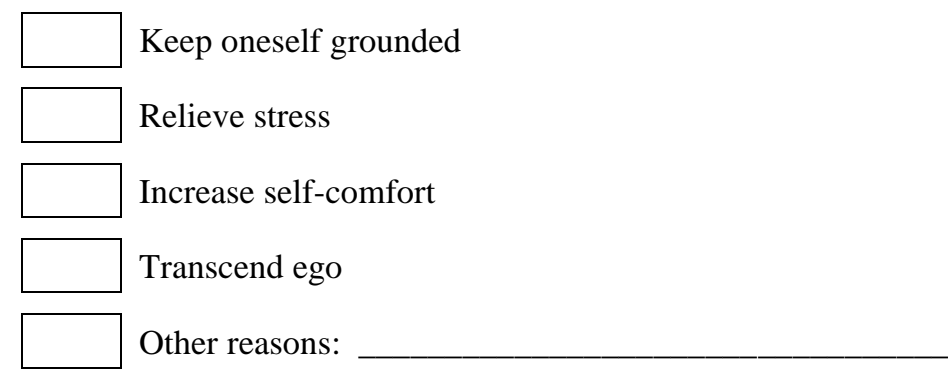

8. I have the WILL to learn correct ways of meditating independently BEFORE/AFTER the workshop

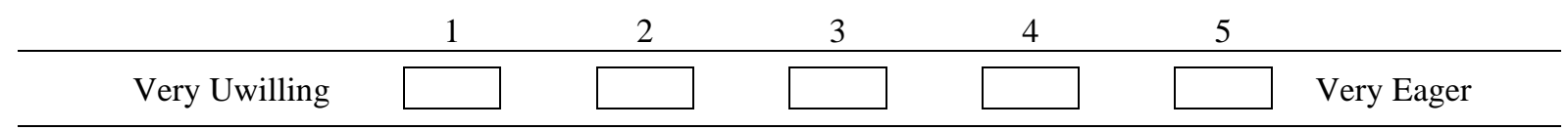


9. I have the a good UNDERSTANDING on the correct ways of meditating BEFORE/AFTER the workshop

\begin{tabular}{lllllll} 
& 1 & 2 & 3 & 4 & 5 \\
\hline Very Poor & & & & 3 & \\
& & & & & \\
\end{tabular}

10. I have the a good ABILITY to meditate correctly BEFORE/AFTER the workshop

\begin{tabular}{llll}
\hline Very Poor $\square \quad \square \quad \square$ & $\square$ \\
\hline
\end{tabular}

\section{Pre-Test and Post-Test Questions}

Choose only one appropriate answer for each questions

1. Which are the three ways of meditating...

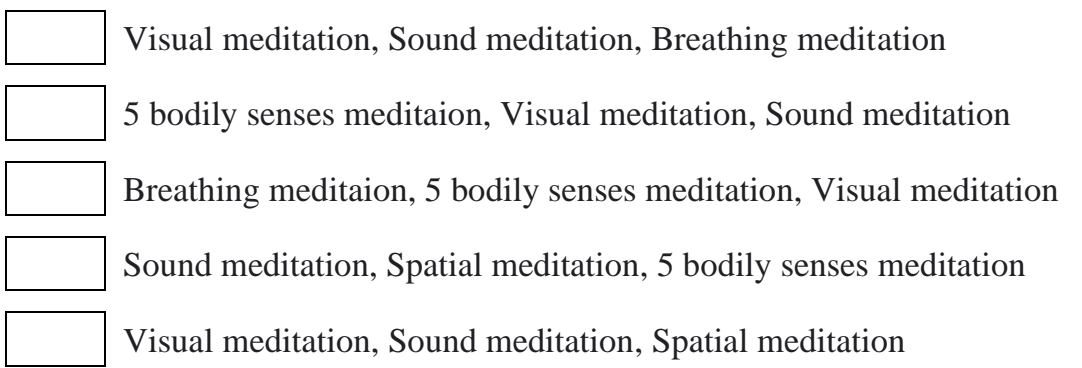

2. Which of these choices is NOT the correct way to meditate...

\begin{tabular}{|c|}
\hline Focus ones attention to a target \\
\hline Maintain attention from time to time \\
\hline Alert when attention is distracted \\
\hline Can return to focus whenever distracted \\
\hline Think the same thoughts over and over \\
\hline
\end{tabular}

3 Which of these choices is NOT the benefit of meditation...

\begin{tabular}{|c|}
\hline Feeling present \\
\hline Releasing stress, anxiety, and feelings of discomfort \\
\hline Regulate breathing \\
\hline Increase comfort \\
\hline
\end{tabular}


Transcend ego

4 Which of these choices is the correct steps of meditation...

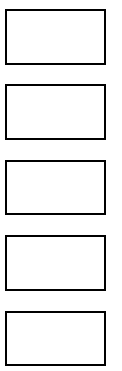

Rigid, Stable, Alert

Stable, Alert, Relaxed

Stable, Relaxed, Flexible

Alert, Flexible, Relaxed

Rigid, Relaxed, Stable

5 Which of these statements is INCORRECT regarding meditation...

\section{Meditation can be likened to exercise for the brain}

All feelings that arise during meditation are valid

One does not have to be $100 \%$ focused

Meditation increases awareness of thoughts, emotions, sounds, and physical sensations

Something has to be felt during meditation 